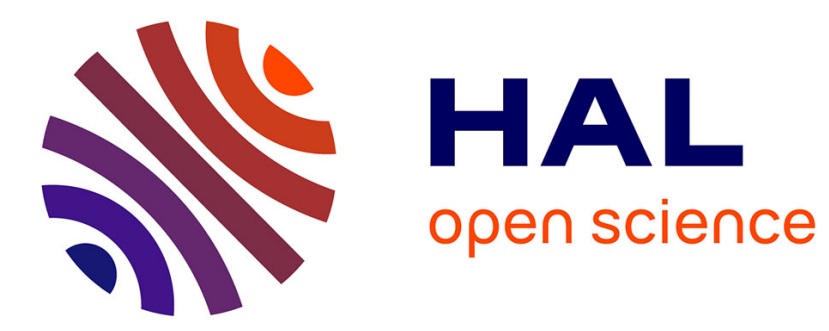

\title{
Is an Increase in the Minimum Retirement Age Always Desirable? The Case of Notional Defined Contribution Systems
}

Riccardo Magnani

\section{- To cite this version:}

Riccardo Magnani. Is an Increase in the Minimum Retirement Age Always Desirable? The Case of Notional Defined Contribution Systems. Metroeconomica, 2016, 10.1111/meca.12113 . hal-01362459

\section{HAL Id: hal-01362459 \\ https://hal.science/hal-01362459}

Submitted on 15 Sep 2016

HAL is a multi-disciplinary open access archive for the deposit and dissemination of scientific research documents, whether they are published or not. The documents may come from teaching and research institutions in France or abroad, or from public or private research centers.
L'archive ouverte pluridisciplinaire HAL, est destinée au dépôt et à la diffusion de documents scientifiques de niveau recherche, publiés ou non, émanant des établissements d'enseignement et de recherche français ou étrangers, des laboratoires publics ou privés. 


\title{
Is an Increase in the Minimum Retirement Age always Desirable? The Case of Notional Defined Contribution Systems
}

\author{
Riccardo Magnani*
}

September, 2015

\begin{abstract}
Several countries have recently introduced reforms that aim to increase the neutrality of their pension system by introducing an incentives-disincentives mechanism or by replacing their traditional defined-benefit system with a Notional Defined Contribution method. This paper evaluates the financial effects of an increase in the minimum retirement age in countries where a Notional Defined Contribution system exists. We show that such a reform produces a positive effect on the financial situation of the pension system (by generating surpluses or by reducing deficits) in the short and in the medium run, but it becomes completely ineffective in the long run. This result implies that in countries where the pension system is sufficiently neutral such a reform is not appropriate to solve the problem of population ageing which is a long-run problem.
\end{abstract}

Keywords: Pension economics; Pension finance; Retirement policies; Minimum retirement age; Notional Defined Contribution systems; Population ageing.

JEL classification: H55; J26.

\footnotetext{
${ }^{*}$ CEPN, Université Paris 13 and Sorbonne Paris Cité. 99, Avenue Jean-Baptiste Clément. 93430 Villetaneuse. France. Tel: +33 (0)1 494038 37. E-mail: riccardo.magnani@univ-paris13.fr. I wish to thank two anonymous referees for their comments that helped to improve the paper. The usual disclaimer applies.
} 


\section{Introduction}

The population ageing problem, observed in most of the industrialized countries, is aggravated by the reduction in the participation rates of individuals aged $55-64 .{ }^{1}$ Empirical and theoretical papers pointed out the negative role that pension plans play on the choice of the retirement age. Traditional PAYG systems, in which pension benefits are generally not linked to contributions, create strong incentives for early retirement and, thus, significant distortions in the labor market (see for example, Burbidge and Robb, 1980; Börsch-Supan and Schnabel, 1998; Gruber and Wise, 1998; Kapteyn and de Vos, 1998).

In order to stimulate the labor participation of the 55-64, several countries introduced financial incentives and disincentives when the retirement occurs after or before the normal age. Other countries, like Sweden and Italy, introduced a Notional Defined Contribution (NDC, hereafter) pension system ${ }^{2}$ which implicitly takes into account this incentives/disincentives mechanism. In particular, NDC systems, that combine actuarial benefit formula with PAYG financing, allow the system to be more neutral by providing a better link between contributions paid and pensions earned and by reducing the tax wedge on labor (Lindbeck and Persson, 2003). Thus, a reform that makes the pension system more neutral would induce individuals to voluntarily choose to work longer. On the other hand, some countries preferred to increase the minimum retirement age, implying that some individuals are obliged to postpone retirement. Some countries such as France, Germany and Italy introduced both a reform that makes the pension system more neutral and a reform that increases the minimum retirement age. In this paper we evaluate the effects of the latter kind of reform, i.e. the financial consequences for the pension system of an increase in the minimum retirement age in an economy where a "neutral" pension system, ${ }^{3}$ such as an NDC system, exists.

Several papers analyze the financial sustainability of an NDC system when the pension system faces demographic and economic shocks (see Valdés-Prieto, 2000, Auerbach and Lee, 2009a and 2009b, Gronchi and Gismondi, 2008). The common result to these analyses is that an NDC system is in equilibrium in steady state, i.e. if the population is stable and the economy is stationary, but not in the short run if a shock hits the economy. This implies that, in the

\footnotetext{
${ }^{1}$ According to the OECD Labour Force Statistics (2008), the employment rate of the 55-64 decreased in Europe from $44 \%$ to $38 \%$ over the period $1980-2000$.

${ }^{2}$ For a review of the main differences between traditional defined-benefits PAYG systems and Notional Defined Contribution systems, see Börsch-Supan (2005).

${ }^{3}$ We write "neutral" in quotation marks since a PAYG system can never be perfectly neutral.
} 
context of population ageing, the presence of a "neutral" system does not guarantee the financial equilibrium of the pension system and additional reforms are necessary. For instance, in the context of a "neutral" pension system, France, Germany and Italy have recently increased the minimum retirement age. The increase of the minimum retirement age, which is generally justified on paternalistic grounds in order to guarantee a sufficiently high level of pension benefits, ${ }^{4}$ contributes to improve the financial situation of the pension system. In the case of a perfectly non-neutral pension system, it is clear that such a reform produces a permanent and positive effect for the pension system. As argued by Lindbeck and Persson (2003), raising the effective retirement age is a powerful way to restore financial stability by simultaneously increasing the number of workers and decreasing the number of eligible pensioners. Andersen (2012) presents an OLG model in which pensions are proportional to the current income, implying that the pension system is perfectly non-neutral. He shows that when population ageing is provoked by an increase in longevity, in order to guarantee the sustainability of the pension system, it is more suitable to increase the retirement age. However, in the context of a "neutral" pension system, raising the pension age has mixed financial effects: in the short run it increases revenues but, as the individuals contribute for more years, they claim larger pensions a few decades later (Valdés-Prieto, 2000). Breyer and Kifmann (2002) analyze the long-run financial implications of an increase in the retirement age in a system characterized by actuarial adjustments and in which the contribution rate adjusts in each period in order to guarantee the equilibrium of the pension system. They consider different levels of the rate of return on contributions and they find that the long-run level of the contribution rate depends on whether the rate of return on contributions is greater, equal, or lower than the GDP growth rate. It is important to highlight that their analysis can be carried out only in the steady state, i.e. when the contribution rate is constant. In contrast, during the transition phase, the value of pension benefits is clearly affected by the change in the contribution rate, which in turn affects the equilibrium contribution rate. $^{5}$

Our analysis differs from that of Breyer and Kifmann (2002) from several aspects. First, the contribution rate is considered as an exogenous variable implying that the change in the retirement age produces, for the pension system, surpluses or deficits. Second, we consider a rate

\footnotetext{
${ }^{4}$ For instance, in NDC systems, an increase in life expectancy induces a reduction in pension benefits. However, this reduction can be avoided if individuals voluntarily choose, or if they are constrained by the law, to work more years.

${ }^{5}$ For instance, given that the increase in the retirement age allows, in the short run, to reduce the equilibrium contribution rate, then the generations who pay a lower amount of contributions will earn lower pension benefits.
} 
of return on contributions exactly equal to the rate of growth of the wage bill since, according to the Aaron-Samuelson condition, ${ }^{6}$ even if the population is stable, an NDC system (and more generally any PAYG system) is financially sustainable only in the case in which the rate of return on contributions is equal to the rate of growth of the wage bill. Finally, we introduce in our model mortality and an earning profile, both differentiated by the age of individuals.

The paper is organized as follows. The next section presents a model where an NDC system exists in an economy that is on its balanced growth path. We first define, in Section 2.1, the computation rules of pension benefits. Then we show in Section 2.2 that, if the economy is on its balanced growth path and if the rate of return on contributions is fixed at the rate of growth of the wage bill, the financial equilibrium of the pension system is guaranteed at each period, according to the Aaron-Samuelson condition. In Section 2.3, we determine the value of the increase in pension benefits that is given to individuals who postpone retirement while, in Section 2.4, we evaluate the effect on the financial situation of the pension system of the increase in the minimum retirement age by one year. We analytically show that the reform produces a surplus for the pension system for a given number of years. However, we also prove that the surpluses generated by the reform fall over time and, after a given number of years, become nil, implying that the positive effect of the reform is only transitory. The theoretical result presented in this paper is obtained by assuming that the population is stable and that the economy is a small-open economy. Both assumptions are necessary to determine an explicit solution. Section 3 presents a numerical analysis in which both hypotheses are removed. Simulation results confirm that a reform that increases the retirement age is ineffective in the long run.

Finally, some countries have recently introduced a reform that increases the minimum retirement age as a reasonable response to the increase in life expectancy. However, the theoretical result presented in our paper has an important implication on the effectiveness of this kind of reform in the presence of a neutral pension system. In fact, in the context of population ageing, implying that the pension system will produce high deficits in the future decades, our result suggests that an increase in the minimum retirement age permits to reduce future pension deficits only in the short run. However, the positive effect decreases over time and, in the long run (i.e. after 30-35 years), the reform becomes completely ineffective. Consequently, a reform introduced in the period 2000-2010 becomes ineffective in the period 2035-2045, i.e. when the population ageing problem will be the most serious for the majority of the European countries.

\footnotetext{
${ }^{6}$ Aaron (1966) and Samuelson (1958).
} 


\section{The model}

Consider a small-open economy in which a representative firm produces one good using a standard Cobb-Douglas technology, $Y_{t}=K_{t}^{\alpha} \cdot L_{t}^{1-\alpha}$, where $Y_{t}$ indicates real GDP, $K_{t}$ the stock of capital available in the economy, and $L_{t}$ the number of units of effective labor. First order conditions for profit maximization require that $w_{t}=(1-\alpha) \cdot\left(K_{t} / L_{t}\right)^{\alpha}$ and $r_{t}+\delta=\alpha \cdot\left(K_{t} / L_{t}\right)^{\alpha-1}$. The small-open-economy assumption implies that the rate of remuneration of capital is exogenously fixed at the world level $\left(r_{t}=r\right)$. Consequently, capital flows adjust in order to keep constant the capital per unit of effective labor $\left(K_{t} / L_{t}=k\right)$. Thus, the wage per unit of effective labor is also constant $\left(w_{t}=w\right)$.

In this economy all individuals start working at age $S+1$, work $N$ years until age $S+N$ and earn pensions benefits starting from age $S+N+1$. We assume that individuals cannot live more than age $S+N+X$, where $X$ represents the maximum number of years during which retirees can earn pension benefits. We suppose that the population growth rate is constant and equal to $n$ and that the survival probabilities, differentiated by age, remain constant over time. This implies that the population is stable, i.e. the old-age dependency ratio and the population structure remain constant over time. The unconditional probability to be alive at age $S+i$ is indicated by $\gamma_{S+i}$, with $\gamma_{S}=1$. The number of individuals aged $S+i$ at time $t+k$ is equal to $\gamma_{S+i} \cdot(1+n)^{k-i}$, implying that the number of individuals aged $S$ at time $t$ is normalized to unity.

The wage earned by an individual, expressed in real terms, is given by the product between the wage per unit of effective labor $(w)$ and a term measuring the individual productivity. In particular, the productivity level of an individual aged $S+i$ at time $t+k$ is given by the product between a term representing the wage profile by age, noted $\eta_{S+i}$, and a term representing the technological level, noted $A_{t+k}$. The earning profile by age is supposed to remain constant over time, while technology is assumed to grow at a constant and exogenous rate $g$. The real wage earned by an individual aged $S+i$ at time $t+k$ is then equal to $\eta_{S+i} \cdot A_{t+k} \cdot w$.

Moreover, in the economy there exists an NDC pension system in which pension benefits are computed according to specific rules, described hereafter, that guarantee the equilibrium of the pension system in each period.

Given all these hypotheses, our economy is on its balanced growth path. 


\subsection{The computation of pension benefits in an NDC system}

Consider an individual who starts working at age $S+1$ at time $t-N+1$ and stops working at age $S+N$ at time $t$. Consequently, the individual begins to pay contributions when aged $S+1$ until when aged $S+N$, the amount of which are respectively $\tau \cdot \eta_{S+1} \cdot A_{t-N+1} \cdot w$ and $\tau \cdot \eta_{S+N} \cdot A_{t} \cdot w$, where $\tau$ represents the social contribution rate. The individual begins to earn pension benefits when aged $S+N+1$ at time $t+1\left(P_{S+N+1, t+1}\right)$ until when aged $S+N+X$ at time $t+X$ $\left(P_{S+N+X, t+X}\right)$. Pension benefits are supposed to be indexed on the basis of inflation implying that pension benefits, in real terms, remain constant over time: $P_{S+N+1, t+1}=P_{S+N+k, t+k}$, with $k=1, \ldots, X{ }^{7}$

In an NDC system, pension benefits are perfectly related to contributions paid. In particular, in our model, pension benefits that the individual earns at age $S+N+1$ at time $t+1$ are computed such that the expected present value of pension benefits is equal to the expected capitalized value of contributions:

$$
\sum_{i=1}^{N} \tau \cdot \eta_{S+i} \cdot A_{t+i-N} \cdot w \cdot(1+R)^{N-i} \cdot \gamma_{S+i}=P_{S+N+1, t+1} \cdot \sum_{i=N+1}^{N+X}(1+R)^{N-i} \cdot \gamma_{S+i}
$$

or, equivalently, by dividing both sides by $\gamma_{S+N+1}$ :

$$
\sum_{i=1}^{N} \tau \cdot \eta_{S+i} \cdot A_{t+i-N} \cdot w \cdot(1+R)^{N-i} \cdot \frac{\gamma_{S+i}}{\gamma_{S+N+1}}=P_{S+N+1, t+1} \cdot \sum_{i=N+1}^{N+X}(1+R)^{N-i} \cdot \frac{\gamma_{S+i}}{\gamma_{S+N+1}}
$$

In the previous expressions, we use a rate of return $R$ both to actualize the pension benefits flows and to capitalize the contributions flows. Thus, $R$ represents the rate of return on contributions that the pension system guarantees to all generations over time and to individuals belonging to the same generation, independently of the retirement age. This particular computation rule of pension benefits guarantees the quasi fairness and the quasi neutrality of the pension system, as shown respectively at the end of Sections 2.2 and 2.3.

The RHS of equation 2 indicates that future (and, given the indexation rule, constant) pension benefits are discounted at the rate $R$ and multiplied by the term $\gamma_{S+i} / \gamma_{S+N+1}$, which represents the probability to be alive at age $S+i$ conditional on being alive at age $S+N+1$. As

\footnotetext{
${ }^{7}$ Another possibility is to index pension benefits on the basis of the wage growth rate. This would imply that the replacement ratio (the ratio between the first pension and the last wage) is lower than in the case considered in our paper while the purchasing power of retirees with respect to that of workers remains constant over time.
} 
shown in the LHS of equation 2, contributions paid at each date are capitalized at the rate $R$ and multiplied by the term $\gamma_{S+i} / \gamma_{N+1}$. This latter term represents the inverse of the probability to be alive at age $S+N+1$ conditional of being alive at age $S+i$. This computational rule allows to take into account the probability that the individual dies before the retirement age. If the individual dies before retiring, all the contributions are lost by the contributor and transferred to the surviving individuals of the same cohort. This mechanism is similar to the insurance mechanism à la Yaari (1965), where surviving individuals obtain a remuneration rate higher than the market interest rate. ${ }^{8}$

Given that the technology grows at the rate $g\left(\right.$ so $\left.A_{t+i-N}=\frac{A_{t}}{(1+g)^{N-i}}\right)$ and that pension benefits remain constant over time, the first pension is computed as follows:

$$
P_{S+N+1, t+1}=\frac{\tau \cdot \sum_{i=1}^{N}\left(\frac{1+R}{1+g}\right)^{N-i} \cdot \eta_{S+i} \cdot \gamma_{S+i}}{\sum_{i=N+1}^{N+X}(1+R)^{N-i} \cdot \gamma_{S+i}} \cdot A_{t} \cdot w
$$

Equation 3 implies that the replacement ratio depends positively on the social contribution rate $\tau$ and the rate of return $R$, and negatively on the survival probabilities $\gamma$.

We analyze next the condition on the rate of return $R$ that guarantees the equilibrium of the pension system in an economy that is on its balanced growth path.

\subsection{The financial equilibrium of an NDC system in a stationary economy}

In order to analyze the financial situation of the pension system, we consider the contributions paid by all workers and the pension benefits earned by all retirees at each year. In what follows, we assume that all individuals work until age $S+N$ and receive pension benefits starting from age $S+N+1$. Thus, $S+N+1$ represents the minimum retirement age fixed by the NDC system.

The financial situation is analyzed at time $t+1$, i.e. the date when the individual considered in the previous section earns his first pension. As mentioned previously in the text, the number of individuals aged $S+i$ at time $t+k$ is equal to $\gamma_{S+i} \cdot(1+n)^{k-i}$. Thus, at time $t+1$, the number of workers is equal to $\sum_{i=1}^{N} \gamma_{S+i} \cdot(1+n)^{1-i}$ and the number of retirees is equal to $\sum_{i=N+1}^{N+X} \gamma_{S+i} \cdot(1+n)^{1-i}$

\footnotetext{
${ }^{8}$ However, other options are available to treat the issue of the death before the retirement age: (i) to allocate survivor benefits to young survivors; (ii) to create a reserve fund that the pension system can use later to cover future deficits.
} 
Proposition 1. In an economy that is on its balanced growth path, if the rate of return on contributions is fixed at the rate of growth of the wage bill, i.e. $1+R=(1+n) \cdot(1+g)$, and pension benefits are computed following the rule indicated in equations 1-3, then, according to the Aaron-Samuelson condition, the NDC system is in equilibrium at each period.

Proof. We first determine the total value of contributions paid by all workers and the total value of pension benefits received by all retirees.

At time $t+1$, the total contributions paid by all workers are equal to $\sum_{i=1}^{N} \tau \cdot \eta_{S+i} \cdot A_{t+1}$. $w \cdot \gamma_{S+i} \cdot(1+n)^{1-i}$.

The total pensions received by all retirees at time $t+1$ are given by $\sum_{i=N+1}^{N+X} P_{S+i, t+1}$. $\gamma_{S+i} \cdot(1+n)^{1-i}$. Given the indexation rule on the basis of inflation, pension benefits earned by one individual remain constant in real terms over the entire pension period. However, considering that productivity grows at the constant rate $g$, pension benefits grow at the rate $g$ from one generation to another. Thus, at time $t+1$, pension benefits earned by a retiree aged $S+i>S+N+1$ can be expressed in terms of the pension earned by a retiree aged $S+N+1$ who retires at time $t+1$ as follows: $P_{S+i, t+1}=\frac{P_{S+N+1, t+1}}{(1+g)^{i-N-1}}$, with $i \geq N+1$. The total pensions paid at time $t+1$ are then given by $P_{S+N+1, t+1} \cdot \sum_{i=N+1}^{N+X} \frac{\gamma_{S+i} \cdot(1+n)^{1-i}}{(1+g)^{i-N-1}}$.

For the pension system, the difference between revenues and expenditures at time $t+1$ is:

$$
\sum_{i=1}^{N} \tau \cdot \eta_{S+i} \cdot A_{t+1} \cdot w \cdot \gamma_{S+i} \cdot(1+n)^{1-i}-P_{S+N+1, t+1} \cdot \sum_{i=N+1}^{N+X} \frac{\gamma_{S+i} \cdot(1+n)^{1-i}}{(1+g)^{i-N-1}}
$$

Using equation 3 and considering that $A_{t+1}=A_{t} \cdot(1+g)$, we find:

$$
\begin{aligned}
& \tau \cdot A_{t} \cdot(1+g) \cdot w \cdot \sum_{i=1}^{N} \eta_{S+i} \cdot \gamma_{S+i} \cdot(1+n)^{1-i} \\
& -\frac{\tau \cdot \sum_{i=1}^{N}\left(\frac{1+R}{1+g}\right)^{N-i} \cdot \eta_{S+i} \cdot \gamma_{S+i}}{\sum_{i=N+1}^{N+X}(1+R)^{N-i} \cdot \gamma_{S+i}} \cdot A_{t} \cdot w \cdot \sum_{i=N+1}^{N+X} \frac{\gamma_{S+i} \cdot(1+n)^{1-i}}{(1+g)^{i-N-1}}
\end{aligned}
$$

By fixing $R$ such that $1+R=(1+g) \cdot(1+n)$, we obtain:

$$
\tau \cdot A_{t} \cdot(1+g) \cdot w \cdot(1+n) \cdot\left\{\sum_{i=1}^{N}(1+n)^{-i} \cdot \eta_{S+i} \cdot \gamma_{S+i}-\sum_{i=1}^{N}(1+n)^{-i} \cdot \eta_{S+i} \cdot \gamma_{S+i}\right\}=0
$$

Q.E.D. 
In Section 2.1 we said that the computation rules presented in equations 1 and 2 guarantee the quasi fairness of the pension system. Actuarial fairness can be defined as a situation in which the present value of lifetime contributions equals the present value of lifetime benefits where the rate of return used is the riskless interest rate (see, for example, Queisser and Whitehouse, 2006, and Disney, 1999). This implies that an NDC system (and, in general, any PAYG system) is actuarially fair only if the rate of return on contributions is equal to the market interest rate. However, Proposition 1 implies that in this case the system is not financially sustainable since, even in an economy that is on its balanced growth path, the pension system would generate deficits at each period. Thus, an NDC system (and, in general, any PAYG system), can never be perfectly actuarially fair ${ }^{9}$ but, at the best, following the definition by Lindbeck and Persson (2003), "quasi actuarial".

\subsection{The effect of an increase in the minimum retirement age on the value of pension benefits in an NDC system}

Consider now a one-year increase in the minimum retirement age. Thus, our individual has to work until age $S+N+1$ at time $t+1$ and earns his first pension when aged $S+N+2$ at time $t+2$. We now compute the new value of pension benefits, noted $P_{S+N+2, t+2}$, such that the expected present value of pension benefits is equal to the expected capitalized value of contributions:

$$
\sum_{i=1}^{N+1} \tau \cdot \eta_{S+i} \cdot A_{t+i-N} \cdot w \cdot(1+R)^{N+1-i} \cdot \gamma_{S+i}=P_{S+N+2, t+2} \cdot \sum_{i=N+2}^{N+X}(1+R)^{N+1-i} \cdot \gamma_{S+i}
$$

The postponement of the retirement age by one year induces an increase $\Delta P_{t+2}$ in pension benefits at date $t+2$ as follows: ${ }^{10}$

$$
\Delta P_{t+2}=\frac{\tau \cdot \eta_{S+N+1} \cdot A_{t+1} \cdot w \cdot \gamma_{S+N+1}+P_{S+N+1, t+1} \cdot \gamma_{S+N+1}}{\sum_{i=N+2}^{N+X}(1+R)^{N+1-i} \cdot \gamma_{S+i}}
$$

\footnotetext{
${ }^{9}$ The only exception is represented by the case in which the golden rule is verified, implying that the interest rate equals the GDP growth rate.

${ }^{10}$ Computational details can be found in Appendix 1.
} 
Equation 5 can be rewritten as follows:

$$
\begin{aligned}
& \Delta P_{t+2} \cdot \sum_{i=N+2}^{N+X}(1+R)^{N+2-i} \cdot \frac{\gamma_{S+i}}{\gamma_{S+N+2}} \\
= & \left(\tau \cdot \eta_{S+N+1} \cdot A_{t+1} \cdot w+P_{S+N+1, t+1}\right) \cdot(1+R) \cdot \frac{\gamma_{S+N+1}}{\gamma_{S+N+2}}
\end{aligned}
$$

The previous expression indicates that if pension benefits are computed such that the expected capitalized value of contributions is equal to the expected present value of pension benefits, the increase in pension benefits that must be given to an individual who works one more year is computed as follows: the expected present value of all the future increases (computed at time $t+2$ and weighted by the probability to be alive at age $S+i$ conditional on being alive at age $S+N+2$ ) must be equal to the additional contributions paid plus the pension benefits lost, capitalized at the rate $R$, and taking into account the probability to survive between age $S+N+1$ and $S+N+2$. This rule guarantees the quasi neutrality of the pension system.

The definition of neutrality given here is similar to that given by Blöndal and Scarpetta (1999) and Queisser and Whitehouse (2006). In particular, Blöndal and Scarpetta (1999) define a neutral system as a system in which the pension wealth of an individual at a given age, computed as the difference between the discounted value of expected pension benefits and the discounted value of contributions, is independent of the retirement age. According to Queisser and Whitehouse (2006) a pension system is actuarially neutral if the pension wealth for retiring a year later is the same as the pension wealth when retiring today plus whatever pension is accrued during the additional year of work. Thus, a system is neutral when the increase in pension benefits is exactly offset by the higher cost in terms of contributions and foregone pensions at all ages (Blöndal and Scarpetta, 1999), implying that the system does not distort the retirement decision. In order to guarantee the actuarial neutrality of the system, the additional contributions paid and the pension benefits lost must then be equal to the present value of all the future increases in pension benefits computed using the riskless interest rate. In contrast, in our paper, the increase in pension benefits, determined from equation 4, is computed using the rate of growth of the wage bill otherwise the pension system is not sustainable, even in an economy that is on its balanced growth path. Consequently, an NDC system, and in general any PAYG system, can never be perfectly neutral but, at the best, "quasi neutral". The computation rules considered in our model guarantee the "quasi neutrality" of the pension system in the sense that 
all the individuals belonging to the same generation receive the same treatment independently of the retirement age, i.e. the same rate of return on contributions, implying that no individual receives a better treatment and no individual is penalized. Finally, it is important to note that the rate of return on contributions is in general lower than the riskless interest rate, implying that the increase in the first pension in an NDC system is lower than in a perfectly neutral system. In contrast, in a perfectly non-neutral system, the increase in the first pension is nil.

\subsection{The effect of the reform on the NDC pension system}

The aim of our paper is to evaluate the effect of the increase in the minimum retirement age in an economy where an NDC system exists. In the previous section we computed the value of the increase in pension benefits that must be given to individuals who postpone retirement by one year in an NDC system. Now we evaluate the financial effects of this reform on the financial situation of the pension system.

Suppose that a reform that increases the retirement age by one year is introduced in $t+1$. This reform implies that all individuals aged $S+N$ at date $t+1$ have to work one more year. Therefore, at date $t+1$, the reform produces a positive gain for the pension system represented by (i) the supplementary contributions paid by the $\gamma_{S+N+1} \cdot(1+n)^{-N}$ workers aged $S+N+1$ at date $t+1$ and (ii) the pension benefits lost by the same individuals. The gain for the pension system is then equal to $\gamma_{S+N+1} \cdot(1+n)^{-N} \cdot\left(\tau \cdot \eta_{S+N+1} \cdot A_{t+1} \cdot w+P_{S+N+1, t+1}\right)$.

At time $t+2$, the gain for the pension system is related to the fact that $\gamma_{S+N+1} \cdot(1+n)^{1-N}$ individuals pay one more year of contributions and do not receive pension benefits. This gain is partially compensated by the fact that $\gamma_{S+N+2} \cdot(1+n)^{-N}$ individuals (the ones who in $t+1$ worked one more year and who are still alive in $t+2$ ) earn a greater amount of pension benefits. The net surplus for the pension system is then equal to $\gamma_{S+N+1} \cdot(1+n)^{1-N} \cdot\left(\tau \cdot \eta_{S+N+1} \cdot A_{t+2}\right.$. $\left.w+P_{S+N+1, t+2}\right)-\gamma_{S+N+2} \cdot(1+n)^{-N} \cdot \Delta P_{t+2}$.

At time $t+3$, the gain for the pension system is related to the fact that $\gamma_{S+N+1} \cdot(1+n)^{2-N}$ individuals pay one more year of contributions and do not receive pension benefits. This gain is partially compensated by the fact that $\gamma_{S+N+3} \cdot(1+n)^{-N}$ individuals (the ones who at date $t+1$ worked one more year and who are still alive at time $t+3)$ and $\gamma_{S+N+2} \cdot(1+n)^{1-N}$ individuals (the ones who at date $t+2$ worked one more year and who are still alive at date $t+3$ ) earn a greater amount of pension benefits. The net surplus for the pension system is then 
equal to $\gamma_{S+N+1} \cdot(1+n)^{2-N} \cdot\left(\tau \cdot \eta_{S+N+1} \cdot A_{t+3} \cdot w+P_{S+N+1, t+3}\right)-\gamma_{S+N+3} \cdot(1+n)^{-N} \cdot \Delta P_{t+2}-$ $\gamma_{S+N+2} \cdot(1+n)^{1-N} \cdot \Delta P_{t+3}$.

More in general, at time $t+k$, the gain for the pension system is related to the fact that $\gamma_{S+N+1} \cdot(1+n)^{k-N-1}$ individuals pay one more year of contributions and do not receive pension benefits. Moreover, $\gamma_{S+N+2} \cdot(1+n)^{k-N-2}$ individuals (the ones who in $t+k-1$ worked one more year and who are still alive in $t+k), \gamma_{S+N+3} \cdot(1+n)^{k-N-3}$ individuals (the ones who in $t+k-2$ worked one more year and who are still alive in $t+k), \ldots$, and $\gamma_{S+N+k} \cdot(1+n)^{-N}$ individuals (the ones who in $t+1$ worked one more year and who are still alive at $t+k$ ) earn a greater amount of pension benefits.

Proposition 2. In an economy that is on its balanced growth path and where an NDC system exists, a reform that increases the minimum retirement age by one year produces positive surpluses for the pension system during $X$ periods, i.e. the maximum number of years in which retires can earn pension benefits. After $X$ periods, the net surplus is nil implying that the reform becomes completely ineffective.

Proof. The net surplus for the pension system at time $t+k$, noted $S u r p l_{t+k}$, is equal to:

$$
\begin{aligned}
\text { Surpl }_{t+k} & =\gamma_{S+N+1} \cdot(1+n)^{k-N-1} \cdot\left(\tau \cdot \eta_{S+N+1} \cdot A_{t+k} \cdot w+P_{S+N+1, t+k}\right) \\
& -\sum_{i=N+2}^{N+k \leq N+X} \gamma_{S+i} \cdot(1+n)^{k-i} \cdot \Delta P_{t+2+k-i+N}
\end{aligned}
$$

where the sum in the RHS of equation 7 takes into account that, given the increase in the minimum retirement age, there cannot be more than $X-1$ generations of retirees at the same date.

Given that the economy is on its balanced growth path and that productivity grows at the constant rate $g$, we have that: (i) $A_{t+k}=A_{t+1} \cdot(1+g)^{k-1}$, (ii) $P_{S+N+1, t+k}=P_{S+N+1, t+1} \cdot(1+$ $g)^{k-1}$, (iii) $\Delta P_{t+2+k-i+N}=\Delta P_{t+2} \cdot(1+g)^{k-i+N}$. Thus:

$$
\begin{aligned}
\text { Surpl }_{t+k} & =\gamma_{S+N+1} \cdot(1+n)^{k-N-1} \cdot(1+g)^{k-1} \cdot\left(\tau \cdot \eta_{S+N+1} \cdot A_{t+1} \cdot w+P_{S+N+1, t+1}\right) \\
& -\Delta P_{t+2} \cdot(1+R)^{k-N-1} \cdot(1+g)^{N} \cdot \sum_{i=N+2}^{N+k \leq N+X}(1+R)^{N+1-i} \cdot \gamma_{S+i}
\end{aligned}
$$


Given that $\Delta P_{t+2}=\frac{\tau \cdot \eta_{S+N+1} \cdot A_{t+1} \cdot w \cdot \gamma_{S+N+1}+P_{S+N+1, t+1} \cdot \gamma_{S+N+1}}{\sum_{i=N+2}^{N+X}(1+R)^{N+1-i} \cdot \gamma_{S+i}}$ (see equation 5 ), the net surplus at date $t+k$ related to a one-year increase in the minimum retirement age is given by:

$$
\begin{aligned}
\text { Surpl }_{t+k}= & \gamma_{S+N+1} \cdot(1+R)^{k-N-1} \cdot(1+g)^{N} \cdot\left(\tau \cdot \eta_{S+N+1} \cdot A_{t+1} \cdot w+P_{S+N+1, t+1}\right) \\
\cdot & \left(1-\frac{\sum_{i=N \leq N+X}^{N+2}(1+R)^{N+1-i} \cdot \gamma_{S+i}}{\sum_{i=N+2}^{N+X}(1+R)^{N+1-i} \cdot \gamma_{S+i}}\right)
\end{aligned}
$$

Equation 8 implies that:

i) If $k<X$, i.e. before date $t+X$, the net surplus is positive.

ii) If $k \geq X$, i.e. starting from date $t+X$, the net surplus is nil.

Q.E.D.

Our analysis can be generalized by assuming that individuals are free to choose the retirement age. Thus, for a given cohort, one fraction of individuals decides to retire at the minimum retirement age, another fraction of individuals decides to retire one year later, and so on. Assuming that these fractions remain constant over time, the theoretical result of our paper still holds. ${ }^{11}$

\section{A simulation exercise}

In this section, we numerically evaluate the financial effects of an increase in the minimum retirement age. The numerical analysis allows to quantify the effects of the reform in the case in which we remove some assumptions made in the theoretical model, i.e. that the population is stable and that the economy is a small-open economy. The numerical analysis is carried out using a simple OLG model of the type Auerbach and Kotlikoff (1987) where several generations coexist at each period. In what follows, we present a brief description of the model.

\subsection{Consumers}

For each generation, we assume the existence of a representative agent who has to decide the intertemporal profile of consumption by maximizing his intertemporal utility subject to an intertemporal budget constraint. All individuals work 41 years, between 20 and 60 years old,

\footnotetext{
${ }^{11}$ This generalization is not presented in the paper since it would extremely complicate the notation. The demonstration is available from the author upon request.
} 
and are retired starting from age 61 until age 95. This implies that, with the notation used in our theoretical model, $S+1=20, N=41$, and $X=35$. The intertemporal utility function is:

$$
U=\sum_{j=20}^{95}\left(\frac{1}{1+\rho}\right)^{j-20} \cdot \ln c_{j, t+j-20} \cdot \gamma_{j, t+j-20}
$$

where $c_{j, t}$ is consumption, $\rho$ is the intertemporal preference rate and $\gamma_{j, t}$ is the unconditional probability to be alive at age $j$ at time $t$.

In order to avoid the presence of involuntary bequests, we assume the existence of a life insurance sector, where the actuarial rate of interest exceeds the market rate of interest by the conditional mortality probability (Yaari, 1965). Individuals accumulate capital over time and, in the last period, they consume all the accumulated capital. The evolution of capital is described by the following equation:

$$
\begin{aligned}
k_{j+1, t+1} & =k_{j, t} \cdot\left(1+r_{t}\right)+\left(1-\omega_{j, t}\right) \cdot k_{j+1, t+1} \\
& +\left(1-\tau-\tau_{t}^{L}\right) \cdot \eta_{j} \cdot A_{t} \cdot w_{t}+P_{j, t}-c_{j, t}
\end{aligned}
$$

where $k_{j, t}$ is the capital that an individual aged $j$ owns at time $t, r_{t}$ is the real interest rate, $\omega_{j, t}$ is the survival probability for an individual belonging to the class age $j$ at time $t, \tau$ is the social contribution rate, $\tau_{t}^{L}$ is the tax rate applied to labor incomes, $\eta_{j} \cdot A_{t} \cdot w_{t}$ is the gross wage earned by an individual aged $j$ at time $t$, and $P_{j, t}$ represents pension benefits which are computed using equation 1.

The Euler equation describing the optimal evolution of consumption is:

$$
\frac{c_{j+1, t+1}}{c_{j, t}}=\frac{1+r_{t+1}}{1+\rho}
$$

The demographic evolution is described by the following equations:

$$
\begin{aligned}
\operatorname{Pop}_{j+1, t+1} & =\operatorname{Pop}_{j, t} \cdot \omega_{j, t} \\
\operatorname{Pop}_{20, t+1} & =\operatorname{Pop}_{20, t} \cdot\left(1+n_{t}\right)
\end{aligned}
$$

where $P o p_{j, t}$ is the number of individuals aged $j$ at time $t, n_{t}$ is a measure of the fertility rate at time $t$ and $\omega_{j, t}$ is the survival probability for an individual belonging to the class age $j$ at time $t$. Fertility rates and survival probabilities can vary over time. 


\section{$3.2 \quad$ Firms}

We assume that a representative firm produces one good using labor and capital according to a Cobb-Douglas production function:

$$
Y_{t}=K_{t}^{\alpha} \cdot L_{t}^{1-\alpha}
$$

where $Y_{t}$ represents real GDP, $K_{t}$ the quantity of capital employed, and $L_{t}$ the quantity of labor employed expressed in effective labor units. The demand of labor and capital is determined in order to maximize profits. First order conditions for profit maximization are $w_{t}=(1-\alpha)$. $\left(K_{t} / L_{t}\right)^{\alpha}$ and $r_{t}+\delta=\alpha \cdot\left(K_{t} / L_{t}\right)^{\alpha-1}$.

\subsection{The pension system and the public sector}

The surplus of the pension system is given by the difference between the contributions earned and the pensions paid:

$$
\operatorname{Surpl}_{t}=\sum_{j} \tau \cdot \eta_{j} \cdot A_{t} \cdot w_{t} \cdot \operatorname{Pop}_{j, t}-\sum_{j} P_{j, t} \cdot \operatorname{Pop}_{j, t}
$$

The public surplus, which includes the pension surplus, is fixed to zero for each period. A tax on labor incomes $\left(\tau_{t}^{L}\right)$ is endogenously determined in order to respect this government budget constraint.

\subsection{Equilibrium}

The equilibrium conditions in the market of goods, in the capital market and in the labor market are:

$$
\begin{aligned}
Y_{t} & =\sum_{j} c_{j, t} \cdot \operatorname{Pop}_{j, t}+I_{t}+N X_{t} \\
K_{t} & =\sum_{j} k_{j, t} \cdot \operatorname{Pop}_{j, t}+K_{t}^{R o W} \\
L_{t} & =\sum_{j} \eta_{j} \cdot A_{t} \cdot \operatorname{Pop}_{j, t}
\end{aligned}
$$

where $I_{t}$ represents investments, $N X_{t}$ net exports and $K_{t}^{R o W}$ the stock of capital owned by foreign residents. 


\subsection{Model calibration}

The productivity growth rate $g$ is fixed at $1.5 \%$. The parameter $\alpha$ is $1 / 3$. The population growth rate $n$ is fixed at $0.5 \%$. The survival probabilities, differentiated by age, are supposed to remain constant over time. ${ }^{12}$ The earning profile by age is constant and generated using the following quadratic function $\eta_{j}=e^{0.08 \cdot(j-S-1)-0.0012 \cdot(j-S-1)^{2}}$. The social contribution rate $\tau$ is fixed at $22.5 \%$. The parameter $\rho$, determined from the Euler equation in order to calibrate the model in steady state, is equal to 0.012 . The rate of return on contributions $R$ used to compute pension benefits in the NDC system is $R=(1+n) \cdot(1+g)-1=2.0075 \%$.

Given these hypotheses, the population is stable and the economy is on its balanced growth path. In particular, the old-age dependency ratio, computed as the ratio between the number of people aged more than 60 and the number of people aged 20-60, remains constant over time and is equal to 0.3 . The replacement ratio remains constant over time and is equal to $50.3 \%$ of the last gross wage. The ratio between the total pension expenditure and GDP is equal to 15\% and the pension system is in equilibrium at each period. This implies that if pension benefits are computed according to equation 1, then the financial sustainability of the pension system is guaranteed in an economy that is on its balanced growth path, as asserted in Proposition 1 and according to the Aaron-Samuelson condition.

\subsection{Simulation results}

Here we simulate the effects of a reform that increases the retirement age by one year. The reform is assumed to be unexpected and is introduced at date $t=41$. We consider four scenarios. In the first scenario, we assume that the economy is a small-open economy. This is exactly the same situation analyzed in the theoretical model in the first part of the paper. In this case, the interest rate is fixed at an exogenous level, while international capital flows are endogenously determined in order to keep the capital per unit of effective labor constant. In the second scenario, we assume that the economy is closed. In this case, international capital flows are set to zero, while the interest rate is endogenously determined in order to clear the domestic capital market. In the third scenario, we assume again that the economy is a small-open economy and, in addition, that population is ageing due to a reduction in fertility rates and an increase in longevity. In the last scenario, we assume that the economy is closed and that population is

\footnotetext{
${ }^{12}$ Survival probabilities are fixed at the level provided by Eurostat for the European Union (28 countries) in 2010 .
} 
ageing as in the third scenario. ${ }^{13}$

Figure 1 in Appendix 2 shows the evolution of the ratio between the surplus of the pension system and real GDP in the first two scenarios, i.e. in the case of an increase in the minimum retirement age by one year, in an open economy (Scenario 1) and in a closed economy (Scenario 2 ), and by considering a stable population. The results are qualitatively identical and quantitatively very similar. In the first year in which individuals have to work one more year, the reform generates a net surplus for the pension system that represents 1.3\% of GDP in Scenario 1 and $1.2 \%$ in Scenario 2. After date $t=41$, the ratio between the surplus of the pension system and real GDP reduces over time in both scenarios. In particular, in Scenario 1, this ratio becomes equal to zero at date $t=75$, i.e. 35 years after the introduction of the reform. Note that 35 years represents the maximum number of years in which retirees can earn pension benefits (since, in our numerical example, individuals earn pension benefits starting from age 61 until age 95) and thus corresponds to the variable $X$ in the theoretical model. This numerical result, in an open economy, is exactly identical to the theoretical result asserted in Proposition 2. In scenario 2 , in which we consider the closed-economy assumption, the result is qualitatively identical, implying that the reform becomes completely ineffective in the long run.

Figure 2 in Appendix 2 shows the evolution of the ratio between the surplus of the pension system and real GDP in the third scenario, i.e. in the case of an increase in the minimum retirement age by one year, in an open economy and by considering an ageing population. Population ageing is simulated by assuming a simultaneous reduction in fertility rates and an increase in longevity. The simulated old-age dependency ratio, represented in figure 4 in Appendix 2, is similar to that projected for Europe. ${ }^{14}$ Scenario 3 is compared with a scenario in which we only simulate the effects of population ageing, i.e. without increasing retirement age. The latter scenario shows that, accordingly to the theoretical result of Gronchi and Gismondi (2008), population ageing produces important deficits implying that an NDC system is not

\footnotetext{
${ }^{13}$ Other interesting extensions of the model, that are not presented in the paper, concern the endogeneity of fertility and the introduction of the consumption/leisure decision. In the context of population ageing, the endogeneity of the fertility rate is clearly an important issue. However, considering that (i) an increase in the minimum retirement age positively affects the present value of lifetime incomes and (ii) that, empirically, per capital GDP and fertility are negatively correlated, then an increase in the minimum retirement age reduces the fertility rate. This implies that the theoretical result of the paper, i.e. that the reform is ineffective in the long term, is reinforced if we treat fertility as endogenous. The simulation model can also be extended by introducing the consumption/leisure decision and, thus, by modifying the intertemporal utility function. However, for all the four scenarios, simulations results are essentially identical as those presented in the paper. Simulation results are available from the author upon request.

${ }^{14}$ According to Eurostat data, the old-age dependency ratio (computed as the ratio between the number of people aged more than 60 and the number of people aged 20-60) would increase from 0.304 in 2015 to 0.531 in 2050 for the European Union (28 countries).
} 
sustainable if the population is not stable. Figure 2 shows that the increase in the minimum retirement age (Scenario 3) permits to reduce pension deficits and thus produces positive effects, but only in the short and medium run. In contrast, after 35 years, the level of pension deficits is exactly the same as in the case in which the reform is not introduced. This implies that the reform becomes ineffective in the long run and, consequently, is not sufficient to face the population ageing problem. ${ }^{15}$ The same result is obtained if we assume that the economy is closed. Figure 3 in Appendix 2 compares Scenario 4 with a scenario in which we simulate the effects of population ageing, assuming that the economy is closed. As in Figure 2, the increase in retirement age reduces pension deficits in the short run and is ineffective in the long run.

It is thus possible to conclude that the numerical simulations prove the robustness of the theoretical result (which is obtained by assuming that the population is stable and the economy is a small-open economy). In fact, by removing both assumptions, a reform that increases the minimum retirement age is ineffective in the long run.

\section{Conclusions}

An increase in the minimum retirement age, which is a reform that may be introduced in order to face the population ageing problem, induces a permanent and positive effect on the financial situation of the pension system only if the system is perfectly non-neutral. In contrast, in the context of a "neutral" pension system such as an NDC system, our paper shows that this kind of reform produces a positive effect only in the short and medium run. In the long run, this reform becomes ineffective in the sense that it does not allow to produce surpluses (or to reduce deficits) with respect to the pre-reform case. In fact, in the case of a "neutral" pension system, individuals who are obliged to work one or more additional years obtain an increase in pension benefits (such that the present value of all the expected increases in pension benefits coincides with the additional contributions paid and the pension benefits lost) and in, the long run, the increase in the pension expenditure compensates the positive effect of the reform.

The result presented in this paper implies that the strategy implemented by some European countries like France, Germany and Italy (i.e. the introduction of a reform that increases the minimum retirement age) is not appropriate given the previous reforms aimed at obtaining a more neutral pension system. In fact, as shown in this paper both theoretically and numeri-

\footnotetext{
${ }^{15}$ Note that pension deficits become equal to zero only when the population becomes stable.
} 
cally, the increase in the minimum retirement age does not permit to solve the long-run financial problem related to population ageing in countries where the pension system is sufficiently neutral. Both the theoretical and the numerical results are consistent with the simulations results presented by the Nucleo di Valutazione della Spesa Previdenziale (Italian Minister of Labor) for the Italian case. Italy introduced an NDC pension system during the Nineties and a reform that increased the minimum retirement age in 2004 and 2007. Simulations show that the reduction in pension deficits, due to the increase in the minimum retirement age, is only transitory and, thirty years after the introduction of this reform, the positive effect of the reform disappears.

Finally, another negative consequence of the reform is in terms of welfare. In fact, an increase in the minimum retirement age provokes a reduction in the utility level of those individuals who are obliged to work more, even if this negative effect is (partially) compensated by the fact that the increase in the present value of lifetime incomes permits to increase consumption.

\section{References}

Aaron, Henry J., (1966), The Social-Insurance Paradox, Canadian Journal of Economics and Political Science, 32 (August), p. 371-374.

Andersen, Torben M., (2012), Fiscal sustainability and demographics - Should we save or work more?, Journal of Macroeconomics, 34, issue 2, p. 264-280.

Auerbach, Alan and Kotlikoff, Laurence, (1987), Dynamic Fiscal Policy. Cambridge University Press.

Auerbach, Alan and Lee, Ronald Demos, (2009a), Notional Defined Contribution Pension Systems in a Stochastic Context: Design and Stability, in Social Security Policy in a Changing Environment, National Bureau of Economic Research, Inc.

Auerbach, Alan and Lee, Ronald Demos, (2009b), Welfare and Generational Equity in Sustainable Unfunded Pension Systems, N. 14682, NBER Working Papers, National Bureau of Economic Research, Inc.

Blöndal, Sveinbjörn and Scarpetta, Stefano, (1999), The Retirement Decision in OECD Countries, N. 202, OECD Economics Department Working Papers, OECD, Economics Department.

Börsch-Supan, Axel, (2005), From traditional DB to notional DC systems: The pension reform process in Sweden, Italy, and Germany, Journal of the European Economic Association, 
3, 2-3, p. 458-465.

Borsch-Supan, Axel and Schnabel, Reinhold, (1998), Social Security and Declining LaborForce Participation in Germany, American Economic Review, 88, issue 2, p. 173-178.

Breyer, Friedrich and Kifmann, Mathias, (2002), Incentives to retire later a solution to the social security crisis?, Journal of Pension Economics and Finance, 1, issue 2, p. 111-130.

Burbidge, John and Robb, A. Leslie, (1980), Pensions and Retirement Behaviour, Canadian Journal of Economics, 13, issue 3, p. 421-437.

Disney, Richard, (1999), Notional accounts as a pension reform strategy: an evaluation, Social Protection Discussion Papers, 21302, The World Bank.

Eurostat. Population and social conditions. http://ec.europa.eu/eurostat/data/database

Gronchi, Sandro and Gismondi, Fulvio, (2008), Backward-looking and forward-looking notionaldefined-contribution pension schemes, Journal of Public Finance and Public Choice, 2008, n.2-3.

Gruber, Jonathan and Wise, David, (1998), Social Security and Retirement: An International Comparison, American Economic Review, 88, issue 2, p. 158-163.

Kapteyn, Arie and de Vos, Klaas, (1998), Social Security and Labor-Force Participation in the Netherlands, American Economic Review, 88, issue 2, p. 164-167.

Lindbeck, Assar and Persson, Mats, (2003), The Gains from Pension Reform, Journal of Economic Literature, 41, issue 1, p.74-112.

Nucleo di Valutazione della Spesa Previdenziale, (2006), Gli andamenti finanziari del sistema pensionistico obbligatorio.

OECD Labour Force Statistics: 1987-2007, 2008 Edition.

Queisser, Monika and Whitehouse, Edward, (2006), Neutral or Fair?: Actuarial Concepts and Pension-System Design, OECD Social, Employment and Migration Working Papers, 40, OECD Publishing.

Samuelson, Paul A., (1958), An Exact Consumption-Loan Model of Interest with or without the Social Contrivance of Money, Journal of Political Economy, 66 (December) pp. 467-482.

Valdés-Prieto, Salvador, (2000), The Financial Stability of Notional Account Pensions, Scandinavian Journal of Economics, 102, issue 3, p.395-417.

Yaari, Menahem E., (1965), Uncertain lifetime, life insurance, and the theory of the consumer, Review of Economic Studies, 32, p.137-150. 
Appendix 1. Computation of the value of the increase in pension benefits due to a postponement of the retirement age by one year.

The term in the LHS of equation 4 can be written in the following way:

$$
\tau \cdot \eta_{S+N+1} \cdot A_{t+1} \cdot w \cdot \gamma_{S+N+1}+(1+R) \cdot \sum_{i=1}^{N} \tau \cdot \eta_{S+i} \cdot A_{t+i-N} \cdot w \cdot(1+R)^{N-i} \cdot \gamma_{S+i}
$$

The term $P_{S+N+2, t+2}$ in equation 4 can be decomposed as follows: $P_{S+N+2, t+2}=P_{S+N+1, t+1}+$ $\Delta P_{t+2}$, where $\Delta P_{t+2}$ represents the increase in pension benefits obtained at date $t+2$ due to a postponement of the retirement age by one year. Thus, the term in the RHS of equation 4 can be written in the following way:

$$
\begin{aligned}
& \left(P_{S+N+1, t+1}+\Delta P_{t+2}\right) \cdot \sum_{i=N+2}^{N+X}(1+R)^{N+1-i} \cdot \gamma_{S+i} \\
= & P_{S+N+1, t+1} \cdot \sum_{i=N+2}^{N+X}(1+R)^{N+1-i} \cdot \gamma_{S+i}+\Delta P_{t+2} \cdot \sum_{i=N+2}^{N+X}(1+R)^{N+1-i} \cdot \gamma_{S+i} \\
= & P_{S+N+1, t+1} \cdot(1+R) \cdot \sum_{i=N+2}^{N+X}(1+R)^{N-i} \cdot \gamma_{S+i}+\Delta P_{t+2} \cdot \sum_{i=N+2}^{N+X}(1+R)^{N+1-i} \cdot \gamma_{S+i}
\end{aligned}
$$

By adding and subtracting the term $P_{S+N+1, t+1} \cdot \gamma_{S+N+1},{ }^{16}$ we find:

$$
\begin{aligned}
& \left\{P_{S+N+1, t+1} \cdot(1+R) \cdot \sum_{i=N+1}^{N+X}(1+R)^{N-i}-P_{S+N+1, t+1} \cdot \gamma_{S+N+1}\right\} \\
+ & \left\{\Delta P_{t+2} \cdot \sum_{i=N+2}^{N+X}(1+R)^{N+1-i} \cdot \gamma_{S+i}\right\}
\end{aligned}
$$

Thus, equation 4 becomes:

$$
\begin{aligned}
& \tau \cdot \eta_{S+N+1} \cdot A_{t+1} \cdot w \cdot \gamma_{S+N+1}+(1+R) \cdot \sum_{i=1}^{N} \tau \cdot \eta_{S+i} \cdot A_{t+i-N} \cdot w \cdot(1+R)^{N-i} \cdot \gamma_{S+i} \\
= & P_{S+N+1, t+1} \cdot(1+R) \cdot \sum_{i=N+1}^{N+X}(1+R)^{N-i}-P_{S+N+1, t+1} \cdot \gamma_{S+N+1} \\
+ & \Delta P_{t+2} \cdot \sum_{i=N+2}^{N+X}(1+R)^{N+1-i} \cdot \gamma_{S+i}
\end{aligned}
$$

\footnotetext{
${ }^{16}$ Note that $P_{S+N+1, t+1} \cdot \gamma_{S+N+1}=P_{S+N+1, t+1} \cdot(1+R) \cdot(1+R)^{N-(N+1)} \cdot \gamma_{S+N+1}$.
} 
Given that, using equation $1,(1+R) \cdot \sum_{i=1}^{N} \tau \cdot \eta_{S+i} \cdot A_{t+i-N} \cdot w \cdot(1+R)^{N-i} \cdot \gamma_{S+i}$ is equal to $P_{S+N+1, t+1} \cdot(1+R) \cdot \sum_{i=N+1}^{N+X}(1+R)^{N-i} \cdot \gamma_{S+i}$, we find that the increase in pension benefits $\left(\Delta P_{t+2}\right)$ satisfies the following relation:

$$
\begin{aligned}
& \tau \cdot \eta_{S+N+1} \cdot A_{t+1} \cdot w \cdot \gamma_{S+N+1}+P_{S+N+1, t+1} \cdot \gamma_{S+N+1} \\
= & \Delta P_{t+2} \cdot \sum_{i=N+2}^{N+X}(1+R)^{N+1-i} \cdot \gamma_{S+i}
\end{aligned}
$$

Thus:

$$
\Delta P_{t+2}=\frac{\tau \cdot \eta_{S+N+1} \cdot A_{t+1} \cdot w \cdot \gamma_{S+N+1}+P_{S+N+1, t+1} \cdot \gamma_{S+N+1}}{\sum_{i=N+2}^{N+X}(1+R)^{N+1-i} \cdot \gamma_{S+i}}
$$


Appendix 2. Simulation results using an OLG model

Figure 1: Surplus of the pension system / GDP

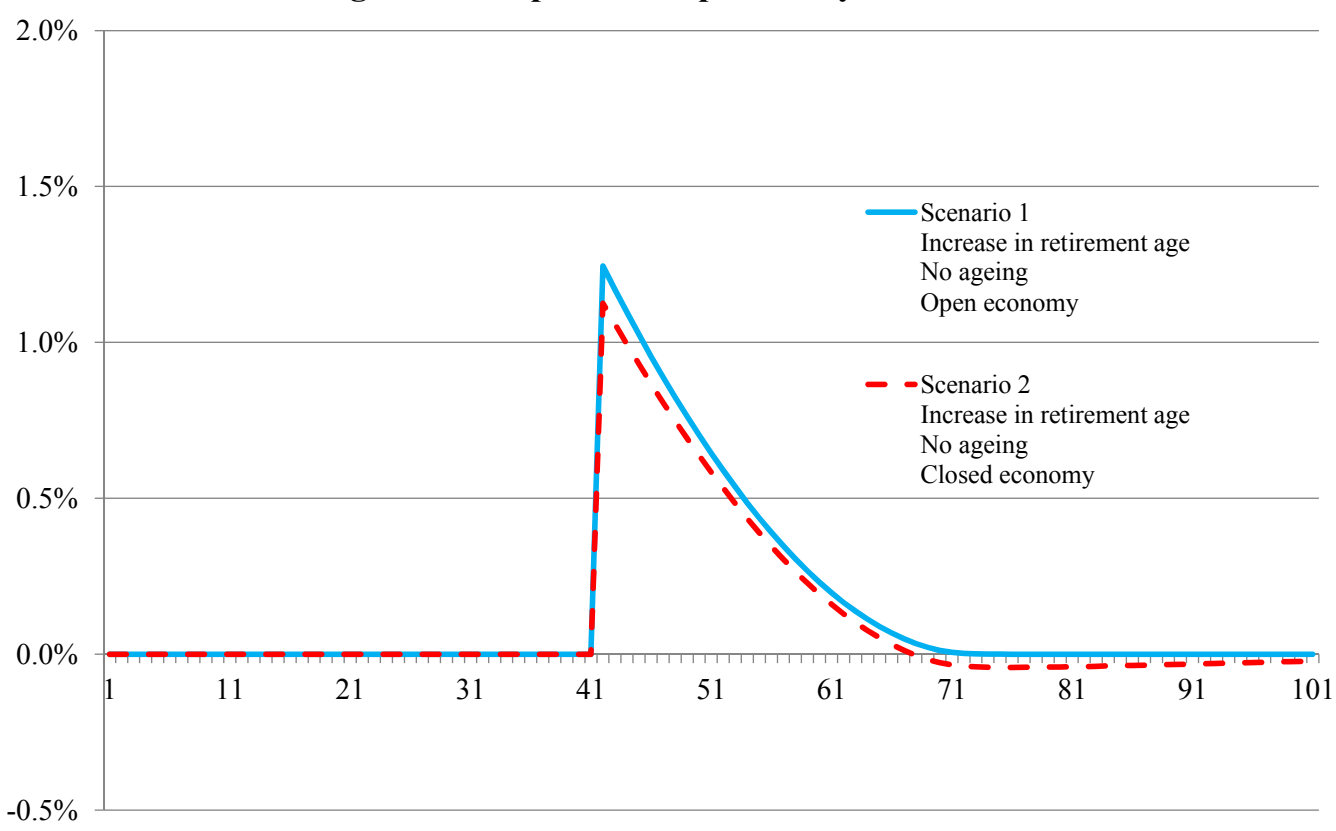

Figure 2: Surplus of the pension system / GDP

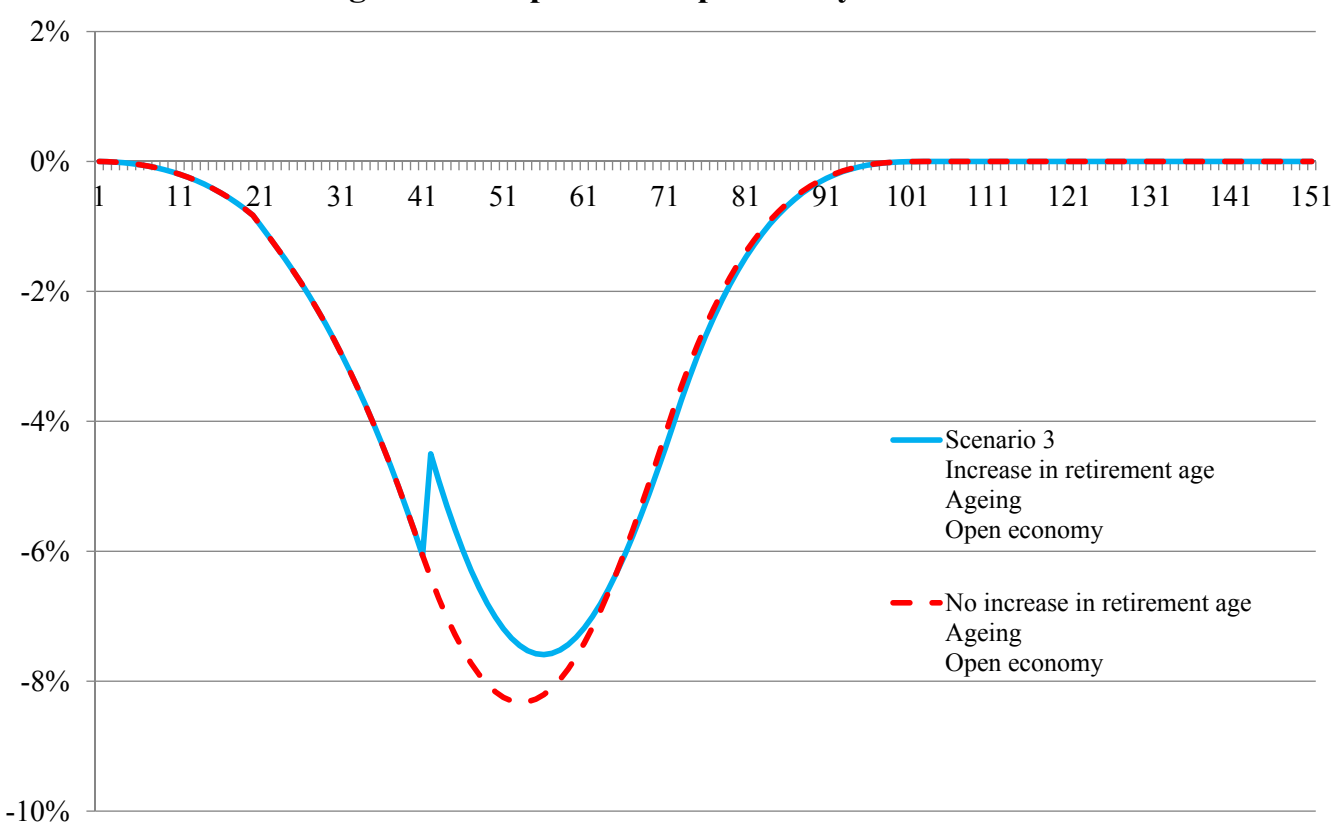


Figure 3: Surplus of the pension system / GDP

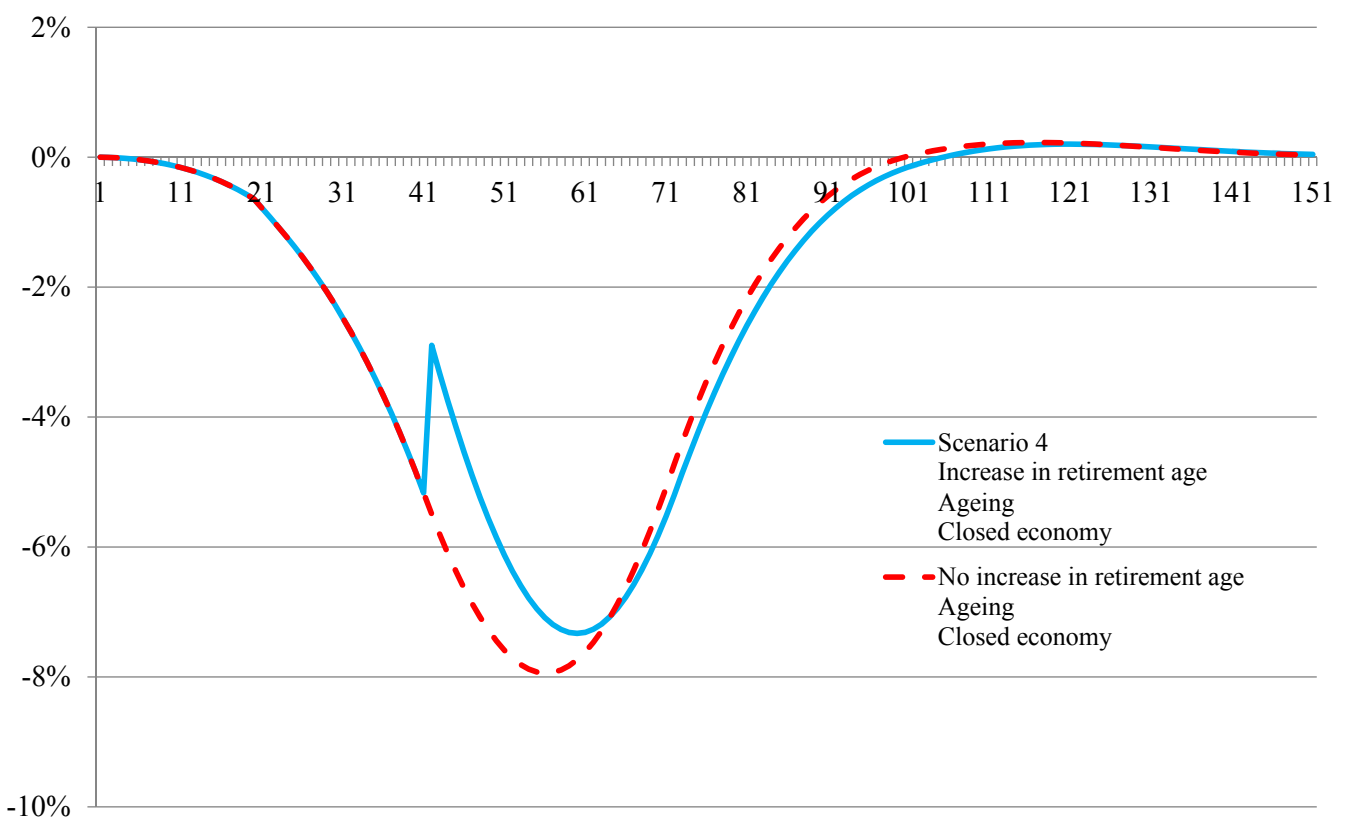

Figure 4: Old-age dependency ratio

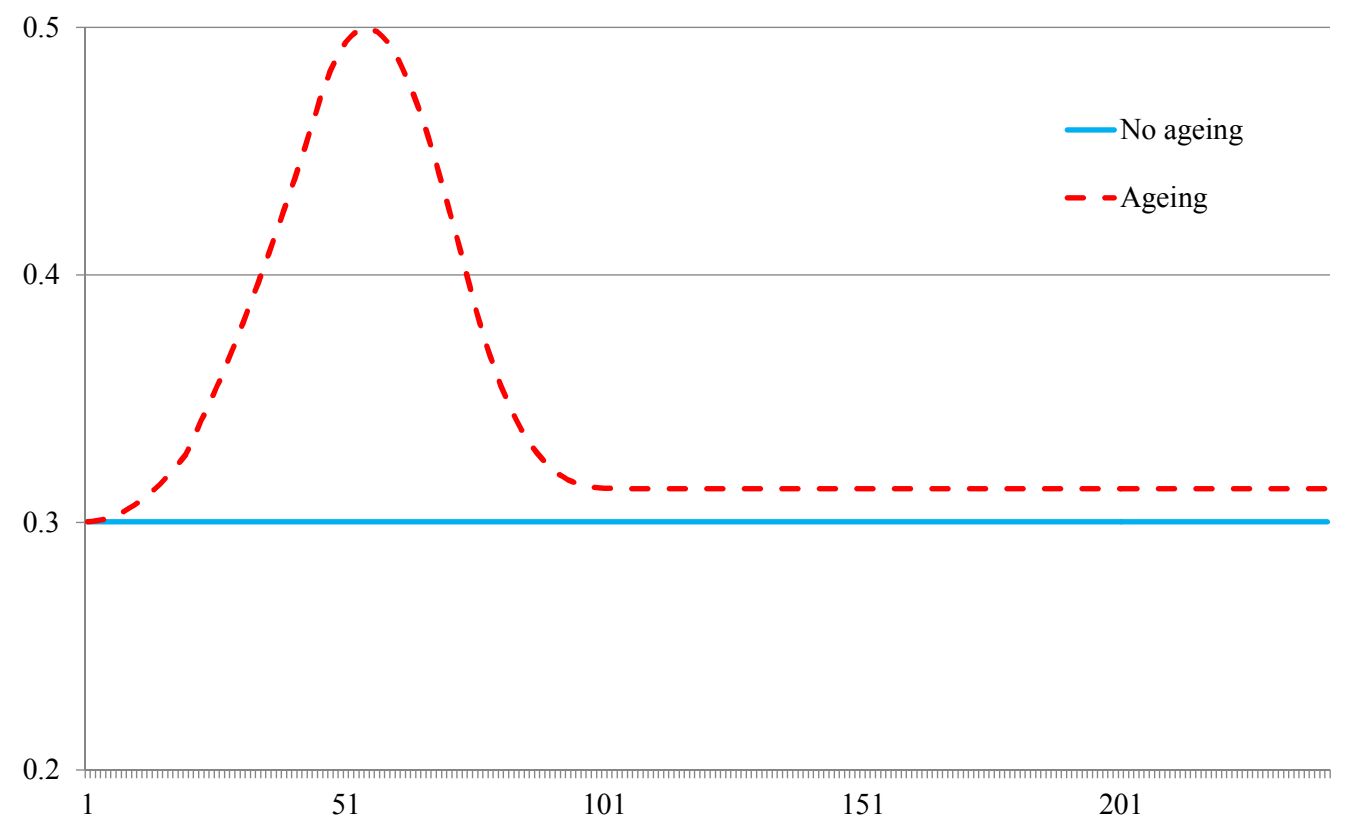

